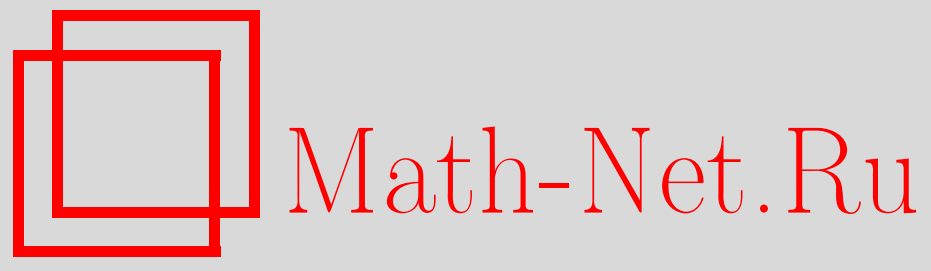

Л. Ашкинази, Ртуть и вода - диффузия и испарение, Квант, 2021, номер 1, 42-44

DOI: https://doi.org/10.4213/kvant20210104

Использование Общероссийского математического портала Math-Net.Ru подразумевает, что вы прочитали и согласны с пользовательским соглашением http://www.mathnet.ru/rus/agreement

Параметры загрузки:

IP : 3.93 .64 .190

26 апреля 2023 г., 11:55:40

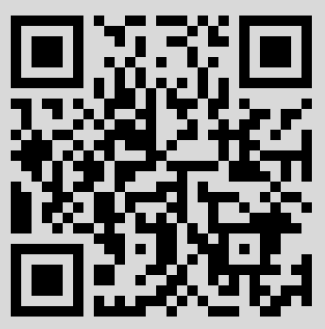




\section{Ртуть и вода - диффузия и испарение}

\section{Л.АШКИНАЗИ}

$\mathrm{T}^{0}$ О, ЧТО ПАРЫ РТУТИ ВРЕДНЫ, ЗНА-

ют все. Поэтому, если ртуть находится в емкости, из которой она может испариться и попасть в помещение, где находятся люди, в эту емкость доливают некоторое количество воды. Вода, как вы знаете, легче ртути приблизительно в 13,6 раз, она располагается поверх ртути и тормозит испарение. Все кажется понятным, однако мы уже сказали несколько несуразностей.

Вода действительно легче, но из этого не следует, что она «располагается поверх». Спирт и ацетон легче воды, но они не располагаются поверх, а растворяются в воде. Причем их растворимость ничем не ограничена, в таких случаях обычно говорят: «смешиваются во всех соотношениях». А вот бензин располагается поверх, но не полностью - растворимость бензина в воде при нормальных условиях около $10^{-5}$ (по весу). А в обратную сторону, т.е. растворимость воды в бензине, около $10^{-4}$. Такие вот у воды и бензина сложные отношения. Что касается взаимной растворимости воды в ртути и ртути в воде, то они невелики: $2 \cdot 10^{-6}$ и $6 \cdot 10^{-8}$ соответственно (опять же, по весу). Так что про воду и ртуть вполне можно сказать «поверх», но это не следует автоматически из того, что вода легче (даже в 13,6 раз).

А откуда мы взяли, что водяное покрытие «тормозит испарение»? Может ли вообще какое-либо покрытие не тормозить, а ускорять испарение? Идея кажется странной, но, скажем, термобелье, надетое на человека, испарение воды (т.е. пота), как пишут, может и ускорять. Там этот эффект если и возникает, то из-за неоднородной структуры - капилляры посредством поверхностного натяжения выводят воду на поверхность,

DOI: https://doi.org/10.4213/kvant20210104 откуда она испаряется. В нашем случае покрытие, т.е. слой воды на ртути, однородно, и подозревать его в таких фокусах не приходится.

Два года назад появилось сообщение, что графен, т.е. монослой углерода (слой толщиной в один атом), подавляет испарение воды с гидрофильных поверхностей и ускоряет испарение с гидрофобных. Правда, считать графен «покрытием» немного странно, уравнение диффузии и обычные принципы расчета здесь неприменимы. Но в нашем случае и это не важно, потому что ртуть не покрывают ни графеном, ни монослоем воды. Так что будем считать, что это обычная вода.

Сначала рассмотрим ситуацию без воды, но в закрытой банке: поверхность ртути открыта, над ртутью есть какое-то количество воздуха, а далее - закрытая крышка. Ртуть испаряется в замкнутый объем воздуха, концентрация ртути в воздухе растет, появляется обратный поток ртути из воздуха в жидкую фазу. Через какое-то время достигается так называемое динамическое равновесие, когда потоки равны, и концентрация ртути в воздухе расти перестает. Эта равновесная концентрация известна; например, при температуре $15^{\circ} \mathrm{C}$ она составляет $2 \cdot 10^{-5}$ кг $/ \mathrm{m}^{3}$. Предельно допустимая концентрация равна $3 \cdot 10^{-10} \kappa г / \mathrm{m}^{3}$, т.е. на 5 порядков меньше. Очевидно, что сидеть в закрытой банке над слоем ртути весьма опасно.

Если ртуть покрыта слоем воды, а за ним находится опять же замкнутый объем воздуха, то ситуация становится сложнее. Концентрация ртути в воде ведет себя так же, как при испарении в замкнутое воздушное пространство - растет до установления динамического равновесия. Однако равновесная концентрация оказывается больше в 3 раза, чем в первом случае, и составляет $6 \cdot 10^{-5}$ кг $/ \mathrm{m}^{3}$. Причин у этого явления может быть две - либо молекулы воды притягивают своим электрическим полем атомы ртути (поляризуя их) и облегчают их отрыв от слоя ртути, либо обратный поток атомов ртути из воды на поверхность ртути при той же концентрации (и температуре) оказывается меньше, чем из воздуха. Оба эти процесса нам скоро потребуются. Какой из этих 
процессов сильнее, не существенно; но важно, что они действуют в одну сторону.

Одновременно с переходом ртути из ее слоя на дне в воду идет аналогичный процесс испарения ртути из воды в воздух. Естественно, он замедляет процесс достижения динамического равновесия в воде. Но как влияет наличие воды на равновесную концентрацию ртути в замкнутом воздушном пространстве над водой с растворенной в ней ртутью? Если на границе воды и воздуха вода вообще «не влияет», то концентрация в воздухе будет такая же, как в воде. Однако в предыдущем абзаце было указано на два возможных процесса - притяжение водой ртути и торможение водой потока атомов ртути. Оба эти процесса уменьшают равновесную концентрацию ртути в воздухе, однако мы не знаем, во сколько раз. Может быть, они влияют и слабо. Во всяком случае, равновесная концентрация - напоминаем, под закрытой крышкой - вроде бы действительно с водой может быть больше, чем без воды. На этом основании в некоторых книжках пишут, что наливать воду в емкость со ртутью бесполезно. Это верно, только если мы собираемся жить и дышать в банке под закрытой крышкой. Но мы ведь этого не делаем!

Реальная ситуация для человека не такая (см. рисунок). Мы находимся в помещении,

\begin{tabular}{|cc|}
\hline Комната & Объем $V$ \\
\hline
\end{tabular}

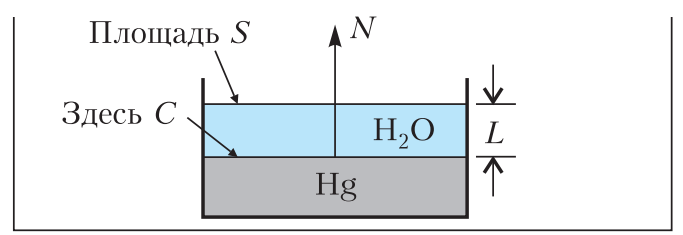

а оно всегда проветривается, даже если окна закрыты. Скорость обмена воздуха в помещении принято характеризовать «кратностью обмена» $n$, т.е. тем, сколько раз сменяется воздух в помещении за некоторое время, обычно за час. В книжках пишут, что кратность обмена должна быть не менее двух раз в час, воздух должен сменяться не более чем за 30 минут, иначе люди начинают чувствовать себя плохо, и совершенно не из-за ртути! Мы будем пользоваться системой единиц СИ и полагать кратность обмена равной $n=5,5 \cdot 10^{-4} \mathrm{c}^{-1}$ соответственно. Итак, наша задача - определить равновесную концентрацию ртути в зависимости от площади поверхности ртути, толщины слоя воды, кратности обмена воздуха в помещении.

Ситуация в воде такова. Уходящий с поверхности ртути в воду поток $N$ определяется условием $N=\omega-u C$, где $\omega-$ скорость покидания атомами ртути поверхности ртути, $u C$ - скорость возвращения атомов ртути из воды в ртуть, $C$ - концентрация ртути в воде на границе с ртутью, $u$ - тепловая скорость. С другой стороны, $N=C D / L$, где $D$ - коэффициент диффузии, $L$ - толщина слоя воды. Это выражение можно считать вариантом определения коэффициента диффузии. Но формула эта приближенная, она написана для случая, когда у наружной поверхности воды концентрация ртути много меньше, чем на границе со слоем ртути. Приравнивая правые части выражений для $N$, получаем

$$
C=\frac{\omega L}{D+u L}, \quad N=\frac{\omega D}{D+u L} .
$$

Проверим полученные формулы на разумность, т.е. посмотрим на поведение ответа при варьировании всех величин. При $\omega=0$ обнуляются и $C$ и $N$, что, очевидно, правильно. При $L=0$ поток $N=\omega$, т.е. происходит свободное испарение, и $C=0$. При $D=0$ концентрация на границе $C=\omega / u$, как и должно быть, а поток $N=0$. При $u=0$ имеем уход с поверхности при запрете возвращения, тогда, естественно, поток $N=\omega$, а концентрация на границе получается $C=\omega L / D$. (Заметим, что при решении любых задач имеет смысл формулы проверять примерно так.) Можно начать немного иначе, сначала разделить два случая, когда $D \ll u L$ и $D \gg u L$, и рассматривать их по отдельности. В общем, метод понятен.

Перейдем к ситуации в помещении. За время $t$ приход ртути в помещение равен $N S t$, где $S$ - площадь поверхности, а уход равен $p V t n$, где $p$ - концентрация в помещении, $V$ - объем помещения, $n$ - кратность обмена, которую будем полагать равной двум в час. Приравнивая приход и уход, находим концентрацию:

$$
p=\frac{N S}{V n}=\frac{\omega D S}{V n(D+u L)} .
$$

Опять же полезно проверить поведение ответа при варьировании всех переменных (вы 
уже понимаете, как это делается). Проведем численные оценки. При $D=10^{-9} \mathrm{~m}^{2} \cdot \mathrm{c}^{-1}$, $L=10^{-2}$ м, $u=150 \mathrm{м} \cdot \mathrm{c}^{-1}$, т.е. при $D \ll u L$, получаем $p=\omega D s /(V n u L)$. Поведение ответа по $\omega, D, S$ - правильное; по $u L$, стремящемся к нулю, натыкается на $D$; по $V n$, стремящемся к нулю, натыкается на ограничение $p \leq C$. Численная оценка при $\omega=$ $=6 \cdot 10^{-5}$ кг $\cdot \mathrm{M}^{-2} \cdot \mathrm{c}^{-1} \quad\left(20^{\circ} \mathrm{C}\right), \quad S=10^{-3} \mathrm{M}^{2}$, $V=50 \mathrm{~m}^{3}, \quad n=5 \cdot 10^{-4} \mathrm{c}^{-1}$ дает $p \approx$ $\approx 1,6 \cdot 10^{-15}$ кг $/ \mathrm{м}^{3}$ при предельно допустимой концентрации $3 \cdot 10^{-10}$ кг $/ \mathrm{m}^{3}$. Таким образом, даже более тонкий слой воды защищает надежно, если, конечно, $n \neq 0$, т.е. у нас помещение с каким-то, хоть плохоньким, но воздухообменом, а не банка с глухой крышкой. Заметим, что без воды, при $L=0$, концентрация $p \approx 2,4 \cdot 10^{-6}$ кг $/ \mathrm{m}^{3}$, а это уже $10^{4}$ предельной - недопустимая ситуация.

Ну и еще посмотрим, за какое время установится равновесие в системе вода-ртуть. Слой воды площадью $S$ и толщиной $L$ с концентрацией ртути на одной границе $C$, а на другой много меньшей содержит количество ртути $C S L / 2$. Это количество поставляется в слой воды потоком $N S$ за искомое время $t=C L /(2 N)$. Подставляя выражения для $C$ и $N$, приведенные выше, получаем $t=L^{2} /(2 D)$. Эта формула позволяет быстро оценивать время диффузионных процессов. В данном случае $t \approx 14$ часов.

\section{М А Т Е А Т И Ч С К Й КР У Ж К}

\section{Задача}

Произволова

о сумме модулей

\section{E. БAKAEB}

Разобьем числа от 1 до 10 на две группы по 5 чисел. Например, так:

$$
\begin{array}{lll}
6, & 2,3,9,7 \\
1, & 5,4,8,10
\end{array}
$$

Упорядочим числа в первой строке по возрастанию, во второй - по убыванию и выпишем разности чисел, стоящих в одном столбце:

$$
\begin{array}{rrr}
2,3, & 6,7, & 9 \\
10, & 8,5, & 4,
\end{array}
$$

разности $-8,5,1,3,8$

Найдем сумму разностей: $8+5+1+3+8=25$.

Сделаем те же действия, но разобьем числа каким-нибудь другим способом (и снова упорядочим):

$$
\begin{array}{r}
1,5,6,8,9 \\
10,7, \quad 4,3,2 \\
\text { разности }-9,2,2, \quad 5,7
\end{array}
$$

Снова найдем сумму разностей: $9+2+2+$ $+5+7=25$. Опять получилось 25 , и это не

DOI: https://doi.org/10.4213/kvant20210105 случайное совпадение - такой ответ будет получаться при любых разбиениях чисел на две группы.

Это утверждение (точнее, его обобщение для произвольного четного количества чисел) - задача Вячеслава Викторовича Произволова со Всесоюзной олимпиады школьников 1985 года. Мы разберем ее решение и попутно обсудим другие задачи, в том числе встречавшиеся на олимпиадах. Начнем с такой.

Задача 1 (А.Шаповалов, Всероссийская олимпиада, 1998). На столе лежали две колодь, по 36 карт в каждой. Первую колоду перетасовали и положили на вторую. Затем для каждой карты первой колоды посчитали количество карт между ней и такой же картой второй колоды (т.е. сколько карт между семерками червей, между дамами пик и так далее). Чему равна сумма 36 полученных чисел?

Решение. Если порядок карт в колодах одинаковый, то между какой-то картой одной колоды и такой же картой другой колоды находится 35 карт, значит, сумма всех 36 чисел равна $35 \cdot 36=1260$. (Если карт в колодах не по 36 , а по $n$, то аналогично получим ответ $(n-1) n$.) Докажем, что сумма будет такой при любом расположении карт.

Первый способ. Используем прием, который часто помогает, когда надо доказать, что 